\title{
Re-emergence of distributed generation in electric power systems: incentives, values and issues
}

\begin{abstract}
Delivery of electrical power to the end users by the wires systems (grids) has been in practice for more than seven decades. However, recent global renewed interest in distributed generation is due to the constraints or shortcomings of this traditional method. These range from the environmental impact of the fossil-fired conventional power plants, unreliability of this system since the long transmission lines are vulnerable to natural hazards which could result to cascading power system failures, to public opposition to upgrading of the existing or installation of new transmission lines whenever the need arises. This paper reviews the main drivers for the renewed global interest in distributed generation; the values that could be derived from adopting this technology, from various perspectives; as well as the factors militating against it despite the potential benefits.
\end{abstract}

Keyword: Distributed generation; Reliability; Benefits; Market deregulation; Power quality; Peak shaving 